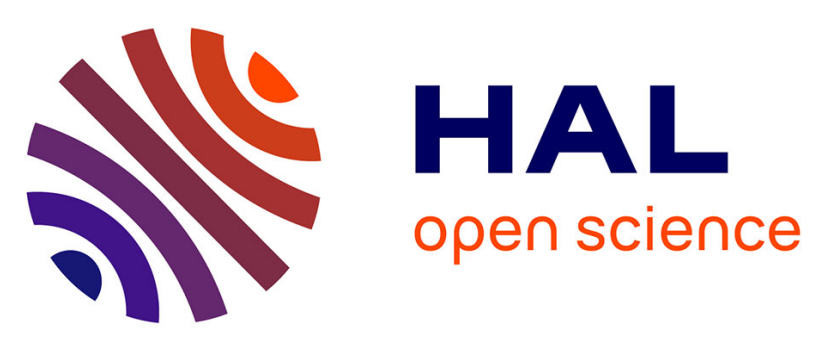

\title{
Chirality in nuclear structure: An experimental view into underlying symmetries \\ C.M. Petrache
}

\section{To cite this version:}

C.M. Petrache. Chirality in nuclear structure: An experimental view into underlying symmetries. International Conference on Frontiers of Nuclear Structure, Jun 2006, Shangai, China. pp.1897-1898, 10.1142/S0218301306005320 . in2p3-00134449

HAL Id: in2p3-00134449

https://hal.in2p3.fr/in2p3-00134449

Submitted on 2 Mar 2007

HAL is a multi-disciplinary open access archive for the deposit and dissemination of scientific research documents, whether they are published or not. The documents may come from teaching and research institutions in France or abroad, or from public or private research centers.
L'archive ouverte pluridisciplinaire HAL, est destinée au dépôt et à la diffusion de documents scientifiques de niveau recherche, publiés ou non, émanant des établissements d'enseignement et de recherche français ou étrangers, des laboratoires publics ou privés. 


\title{
CHIRALITY IN NUCLEAR STRUCTURE: AN EXPERIMENTAL VIEW INTO UNDERLYING SYMMETRIES
}

\author{
C.M. PETRACHE * \\ Department of Physics, University of Camerino, and INFN, Sezione di Perugia, Italy \\ costel.petrache@unicam.it \\ Received (received date) \\ Revised (revised date)
}

\begin{abstract}
The experimental information on the observed nearly degenerate bands in the $\mathrm{N}=75$ isotones, in particular ${ }^{134} \mathrm{Pr}$, which is considered as the best candidate for chiral bands, if critically analyzed, shows that most properties of the bands, in particular the recently measured branching ratios and lifetimes, are in clear disagreement with the interpretation of the two bands as chiral bands. For I $=14-18$ in ${ }^{134} \mathrm{Pr}$, where the observed energies are almost degenerate, a value of 2.0(4) for the ratio of the transition quadrupole moments of the two bands was obtained, which implies a considerable difference in the nuclear shape associated with the two bands. The insufficiency of the near-degeneracy criterion to trace nuclear chirality is clearly emphasized.
\end{abstract}

The experimental information on the observed nearly degenerate bands in the $\mathrm{N}=75$ isotones, in particular ${ }^{134} \mathrm{Pr}$ and ${ }^{136} \mathrm{Pm}$, which are often considered as the best candidates for chiral bands, is critically analyzed. The apparent near degeneracy of the two bands, the energy signature staggering, the particle alignments for the two bands, the crossing frequencies and branching ratios in the crossing region are discussed for the two nuclei ${ }^{1}$. Most properties of the bands in ${ }^{134} \mathrm{Pr}$, in particular the recently measured branching ratios ${ }^{2}$ and lifetimes ${ }^{3}$, are in clear disagreement with the interpretation of the two bands as chiral bands. For $\mathrm{I}=14-18$ in ${ }^{134} \mathrm{Pr}$, where the energies are almost degenerate, we have analyzed the measured energy differences and out-of-band to in-band branching ratios of stretched quadrupole transitions assuming that the states are mixed, caused by a 2-state interaction with no off-diagonal E2 matrix elements. Thereby one can determine correlated values of the interaction strength, $|\mathrm{V}|$ and the ratio of intrinsic E2 transition moments of the two unperturbed bands. A value of $\mathrm{Q}_{1} / \mathrm{Q}_{2}=2.0(4)$ for the ratio of the transition quadrupole moments of the two bands was obtained, and an interaction strength $|\mathrm{V}|$ of $13 \mathrm{keV}$ and $17 \mathrm{keV}$ for odd and even spins, respectively (see Fig. 1).

*Present address: Institute de Physique Nucléaire, CNRS-IN2P3, Université Paris-Sud XI, 91406 Orsay cedex, France; petrache@ipno.in2p3.fr 

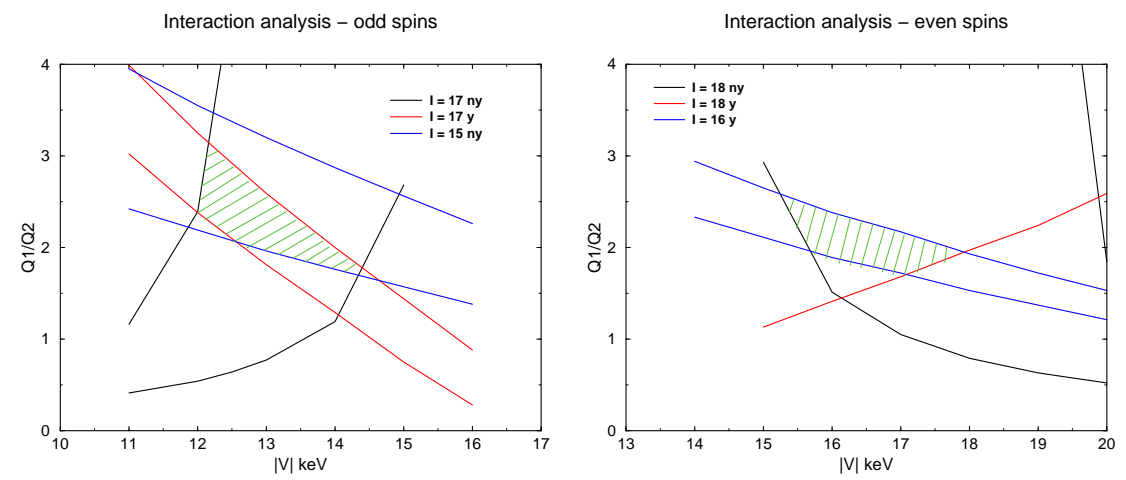

Fig. 1. Ratio of unperturbed $\mathrm{E} 2$ transition moments $\mathrm{Q}_{1} / \mathrm{Q}_{2}$ vs interaction strength $|\mathrm{V}|$ in the crossing region. Data for yrast and non-yrast initial states are denoted by y and ny, respectively. The shaded area shows the values allowed by the experimental data.

We note that the quantities used in analysis of the crossing between the two bands are not based on the assumption of a rigid shape. Thus, there must be a significant difference in the shapes associated with the two bands and it is therefore questionable if and to what extent a reminiscence of the chiral geometry is present in the ${ }^{134} \mathrm{Pr}$ data. Though chiral twin bands are theoretically expected to appear under specific circumstances, the present type of critical analysis should be applied also to other cases of many available publications in which the chiral interpretation is claimed. The insufficiency of the near-degeneracy criterion to trace nuclear chirality is clearly demonstrated.

\section{References}

1. C. M. Petrache, G.B. Hagemann, I. Hamamoto, K. Starosta, Phys. Rev. Lett. 96 (2006) 112502 .

2. GS2K009 Collaboration, K. Starosta et al., Proceedings of the International Nuclear Physics Conference, Berkeley, California, 2001, AIP Conf. Proc. No. 610, ed. E. Norman, (AIP, New York, 2002), p. 815.

3. D. Tonev et al., Nuclei at the Limits, Argonne, Illinois, 2004, AIP Conf. Proc. No. 764, eds. D. Seweryniak and T.L. Khoo, (AIP, Melville, New York, 2005), p. 93, and Phys. Rev. Lett. 96 (2006) 052501. 